\title{
A CONTRIBUIÇÃo DA PRÁTICA DE ENSINO DE GEOGRAFIA NA AUTONOMIZAÇÃO DE ALUNOS E FUTUROS PROFESSORES
}

Augusto Cesar Pinheiro da Silva

Sou professor há vinte anos atuando em sala de aula, trabalhando com Ensino Básico. Apesar de algumas dificuldades nessa atuação, também existem reconhecimentos que permitem vislumbrar valores bastante significativos. Não dispenso, de forma alguma, o trabalho com a formação de crianças no nível de Ensino Fundamental, em especial, aquelas que estão entre o sexto e o novo ano, tendo, sempre como preocupação o conhecimento geográfico.

Considero isso importante, pois se trata de um envolvimento profissional e de formação social, o qual o professor de geografia não pode perder de vista. Muitas vezes, utilizamos a licenciatura como um degrau, um momento inicial de formação, onde depois se esquece como os professores iniciam sua prática pedagógica com alunos desse nível de formação. Não se pode esquecer a necessária formação continuada. $\mathrm{Na}$ verdade, quanto mais qualificados forem os licenciados tanto mais estarão preparados na ciência que então escolheram; quanto mais aprofundado for o conhecimento, os métodos e as técnicas, tanto maior será a capacidade de liderança em termos de pesquisa, ou produção de materiais voltados para educação básica.

Isso é de estrema importância e uma recomendação que deve ser colocada para aqueles que iniciaram a carreira docente há pouco tempo (ou que irão iniciá-la).

Tenho orgulho de ser professor e nesse momento apresento um relato envolvendo uma ideia geral que cobre esses vinte anos em que tenho atuado como professor, tendo como ênfase a proposta pedagógica de formação, destacadamente, na grande área de ciências humanas. O contexto escolhido é o das transformações recentes, assim como as demandas sociais que então se descortinam. Acrescento a esse relato uma breve discussão sobre a legislação, relacionando-a às grades curriculares da formação de professores no Brasil.

Desse modo, aqui estão presentes minhas considerações de como o currículo de professores deveria ser; a forma pela qual a universidade deveria pautar a produção de um profissional que lida com a criança na Educação Básica; como esse profissional deveria ser formado; as demandas subjacentes ao profissional de ciências humanas frente aos desafios pressupostos na sociedade contemporânea.

Inicialmente gostaria de colocar em perspectiva os fundamentos teóricos que norteiam os pensamentos que estão aqui arrolados e nos quais se baseiam a formação de professores no Brasil, enfatizando mais exatamente as práticas políticas sobre as trocas e os embates que vão estabelecendo condições para se formar uma criança autônoma. É necessário considerar a forma em que o ambiente vivido por ela é um somatório de vitorias, derrotas e desejos que são ou não alcançados. É exatamente sobre estas relações que o mundo real e concreto vai se fazendo. É nele que o ser constrói uma realidade própria. Nesse sentido, vejo a formação de professores no Brasil e as correlatas mudanças em andamento e que vão sendo percebidas nas Leis de Diretrizes e Bases de 1996. É possível inferir que se contempla uma necessidade de pensar o currículo pautado nas realidades locais e nesse sentido deve ser priorizada e valorizada a 
contextualização do vivido. Não se pode mais conceber professores formados por unidades e estratégias únicas de formação geral.

De fato, o Brasil é um país extremamente complexo e diverso. Existe no Brasil uma gama de diferenças e assim os currículos nas universidades precisam ter não apenas a participação significante dos professore da área de licenciatura, mas deve acrescentar a participação dos alunos na elaboração e discussão dessa grade.

É perceptível que uma grade de formação tem que fazer valer os trabalhos existentes no âmbito da localidade. Um dos muitos exemplos é o trabalho sobre manguezais que vem sendo realizado pela FEBF (Faculdade de Educação da Baixada Fluminense). Revela-se umas das muitas histórias do município de Duque de Caxias e que pode definitivamente adentrar na formação de seus licenciandos, porque faz parte da pesquisa desenvolvida no lugar, abrindo-se possibilidades de resgatar uma abordagem, dentre as muita existentes.

Nesse sentido, observamos que as Leis de Diretrizes e Bases da Educação Brasileira, possibilitam contemplar a diversidade sem perder de vista a unidade. Os prérequisitos necessariamente é a construção de motivações, incluindo-se as lutas por direitos, porque senão os professores agem sob determinadas estruturas que já se mantêm que, por já estarem postas, vão se repetir nos currículos de formação, empobrecendo-os.

A LDB, nessa perspectiva, apresenta um dos pontos importantíssimos hoje na potencialidade de os currículos universitários trazerem como foco o lugar, um conceito que tanto pode ser explorado pela ciência geográfica quanto pelas ciências que contemplam a educação ambiental. $O$ enfoque deve ser sobre a formação de um professor que mobilize suas experiências pedagógicas, teóricas e práticas de acordo com a realidade da localidade.

A FEBF, assim, deve privilegiar a reflexão sobre a realidade desse local, da Baixada Fluminense, no caso aqui destacado, o fundo da Baía da Guanabara, lembrando-se que não podem ser esquecidos os sujeitos que irão trabalhar nas escolas da Educação Básica nos municípios limítrofes às bacias hidrográficas que deságuam nesse acidente geográfico. Nota-se a indissociabilidade entre pesquisa e extensão e ao mesmo tempo a sua necessária vinculação à licenciatura. Este deve ser o foco de lutas do professorado e das universidades que formam professores. Lidar com a realidade vivida pelas crianças que estão envoltas nessa realidade é pesquisar o tempo inteiro.

Atualmente, temos uma linha de pensamento de que a licenciatura tem que ser formada sob nível técnico, inclusive isto está sendo reforçado pela CAPES (Coordenação de Aperfeiçoamento de Pessoal de Ensino Superior) valorizando a pesquisa, em âmbito nacional, voltada para a química e a física, que tende a promover um processo em que a licenciatura constituir-se-ia de uma formação técnica, realizada nas escolas técnicas. Isso vem crescendo muito. Por isso as universidades formadoras de professores precisam tomar muito cuidado, porque em pouco tempo - persistindo essas iniciativas e não existindo contra-pressões - pode ser que não seja mais necessário a formação em "licenciatura" para se tornar professor, sendo necessário apenas um curso técnico de um ano e meio ou dois anos. 
Mais uma vez, emerge a defesa de que o professor deve ser também um pesquisador e evidentemente, comprova-se que não deve haver essa distinção entre ensino e pesquisa. Não pode haver essa dissociação entre pesquisa e extensão. Temos que buscar sempre os fundamentos teóricos e metodológicos que auxiliam nossas praticas educacionais.

Ser um professor de Escola Básica significa ter uma base teórica e metodológica capaz de superar os desafios que estão se mostrando, se apresentando na construção de um profissional que vai lidar com uma realidade extremamente complexa, muitas vezes, materializada na escala local.

A leitura e a busca constante de um referencial teórico na formação do professor se nos apresenta entre os variados caminhos que orientam a procura pela autonomia como profissional de ensino.

E é esse o sentido em que deve estar sedimentada a busca pela reestruturação da formação dos professores. É o que uma universidade precisa propor com a finalidade de ser capaz de enfrentar os desafios apresentados acima e que possam tornar nossos licenciados profissionais capazes de dar conta da prática docente.

Assim, não podemos ter esse pensamento de uma disciplina desintegrada. Penso, em especial, que essa ideia de que o bacharel de geografia é diferente do licenciado em geografia, deve ser superada. Acredito que uma formação integral - que não dissocie ensino, pesquisa e extensão - é vital e que o professor de geografia busque sempre o referencial do bacharelado quanto à pesquisa e a fonte de informação de conhecimentos seja capaz de dar conta de sua formação. O mesmo pode ser estendido aos outros campos do conhecimento, como aqueles do sociólogo, como o do antropólogo, como o do historiador, ou do biólogo. A unidade ensino e pesquisa deve ser o grande foco de uma reformulação curricular.

Nesse sentido, um ensino integrado tem que disponibilizar todo quadro metodológico e conceitual aos profissionais. Claro que essa complexidade que contemple essa formação passa fundamentalmente pelo estágio supervisionado eficiente. E aqui estamos diante de outra luta que precisamos abraçar coletivamente em relação às universidades e notadamente a UERJ. Essa mesma luta se estende pela busca de uma Prática de Ensino eficiente.

Mas, o que seria essa prática de ensino eficiente? Mas do que cumprir horas, cumprir mais de cem, ou trezentas e tantas outras, é necessário cumprir exatamente a missão docente em sala de aula, na divisão de atividades diversas e na capacidade reflexiva que teremos de desenvolver como profissional, que é estar em sala de aula praticando, colocando em prática a docência com experimentos diversos, estratégias metodológicas diversas, que têm, portanto, capacidade de potencializar enfrentamentos em um mundo complexo do trabalho, já que abraçamos aquilo que escolhemos: sermos professores de geografia.

Então o estágio supervisionado deve ter uma perspectiva integrada, mediado pela participação efetiva. Precisamos superar essa ideia de que estágio é sentar no fundo da sala, apenas vendo o professor falar, cumprindo a hora e uma vez terminada a aula, vai-se embora depois de assinar um papelzinho e pronto. $\mathrm{O}$ estágio supervisionado, ao 
contrário do que se tem concebido, é um dos momentos mais valorizados da formação de professores e isso tem de ser cobrado dentro de um curso que forme esse profissional de educação, pois o estágio supervisionado deve primar pela diversificação e não estar restrito a um ambiente da escola clássica, da escola tradicional que pouco valoriza a participação e interação ou que dialogue com organizações não-governamentais e movimentos sociais diversos.

Deve-se, mais uma vez, insistir: na prática social do professor, mais do que o conhecimento das temática didáticas, aponta-se a necessidade deste profissional se inserir no campo das ciências humanas, com o intuito de vermos por outros ângulos os dados da informação social e estamos num ambiente rico para essa intervenção e ação.

Outro momento que fundamentalmente cerca a prática do estágio supervisionado, capaz de dar conta de uma pluralidade de inserção social que temos contato, é aquele em que o Estágio coincide com a pesquisa, pois aqui se estabelece uma ligação com a formação continuada. E este é um dos pontos mais complexos de nossa formação: o professor deve ser também pesquisador. Quantas vezes nós não sentimos ciúmes daquele colega que trabalha com questões administrativas e que às seis horas da tarde de sexta já acabou o expediente e só volta na segunda, ás $8 \mathrm{~h}$ da manhã? $\mathrm{O}$ professor não tem, digamos assim, essa mesma vantagem, pois sua pesquisa continua dentro e fora da sala de aula e mais do que isso, quando se forma não está formado verdadeiramente, pois ele tem que voltar a universidade. Quantos universitários mantêm um vinculo com a universidade mesmo depois de pegar seu diploma? Depois de vinte anos em sala de aula pude ver essa dependência do professor em estar se atualizando e mantendo sua pesquisa, mas mesmo assim descobri que não saberia fazer outra coisa, ou seja, não saberia fazer diferente, pois a minha preocupação pela formação social, os meus comprometimentos e mesmo os meus engajamentos me levaram a ter constantes questionamentos sobre minha responsabilidade como docente, os quais só tinham como encaminhamentos a prática da pesquisa conjugada à prática da sala de aula. E essa participação do professor numa sociedade como a nossa é fundamental, pois somos formadores de opinião e estamos constantemente preocupados com a formação social.

Quem são os profissionais da área de ciência humanas? Penso não apenas nestes, mas notadamente, quando penso na formação geral dos professores do ensino básico, independentemente de sua área de conhecimento, vejo que se requer uma discussão em que a atuação em educação não deve separar ciências humanas e naturais. Creio aqui que todas são "ciências humanas", na medida em que as finalidades são humanas e as pesquisas são realizadas por homens concretos. Como profissionais da área de educação estes profissionais precisam ser intelectualizados não apenas no sentido de se apropriar de leituras que vão contribuir na sua formação, mas esse processo de formação geral envolve a capacitação de entender a realidade social e atuar intelectualmente na formação social.

O contato com o grupo social é fundamental, isto é, se atualizar intelectualmente, de forma que aquilo que está sendo ensinado e praticado no ensino fundamental seja apropriado cognitivamente, pois as situações vividas pela criança se renovam constantemente.

È exatamente esse grupo social - a criança em formação - que precisa ter acesso a nossa base intelectual, tendo como eixo nossa paixão pela atuação e não apenas por 
sermos pessoas preocupadas com a qualidade de vida dele. $\mathrm{O}$ aluno sabe quando o professor é dedicado, quando ele tem uma linha de dedicação de pesquisa e esse aluno passa a se revelar para aquele profissional em sala de aula e o interesse pela descoberta é estimulado, porque o discente também passa a reconhecer a importância da ampliação de suas leituras de mundo. A preocupação como profissional em sala de aula vai contaminá-lo com o seu projeto intelectual de cura, de busca de resolução dos problemas. Esse profissional dedicado, inquieto, nunca vai se esquecido.

Os professores exigentes são professores odiados, porém, nunca esquecidos e isso é muito importante. Não tenhamos medo de sermos muitas vezes o chato, o que incomoda, o que cobra presença, o que dá falta, o que exige provas mais complexas porque futuramente o próprio aluno perceberá que foi exigido dele a construção e produção do conhecimento, portanto, foram cobradas análises mais apuradas e a exigência do mestre acontecia porque realmente estava disposto a desenvolver o projeto pedagógico da equipe e da comunidade escolar, sem esquecermos que é esse o papel do intelectual.

Uma sociedade precisa de intelectuais, não um intelectual encastelado, mas um pensador reflexivo cuja prática seja constante sobre o que será executado em sala de aula. O saber-fazer nesse momento revela aqui a unidade entre teoria e prática. Essa consciência de comprometimentos entre conteúdos, avaliação e responsabilidades dos mestres se espalha e vai se enraizando na vida social dos educandos, fazendo-o pensar em seu papel no futuro e isso ganha uma dimensão que, absolutamente, não deve ser negligenciada. Mais do que ser o professor "bonzinho", o professor que vai para reuniões de lazer no final do dia, é um professor responsável que exige e age com coerência entre o que foi trabalhado e o que vai ser exigido. Eis o sucesso do processo educativo.

Necessário se faz não se perder de vista, vale reforçar, a delicada questão social a qual jamais poderemos dissociá-la da prática educacional. Isso é fundamental, porque a maioria de nós é ou será professor da rede publica, seja de Duque de Caxias ou de outro município da Baixada Fluminense, os quais são palcos de movimentos sociais, onde nossas ações frente às organizações sociais são as mais diversificadas e a sedução do educando por entender essa participação e como ele pode participar passa a se constituir de uma demanda para a reprodução de um estado de luta e de resistência, de conflitos e de tensões para o alcance daquela autonomia de que mencionei anteriormente.

Nesse sentido, estamos buscando mostrar que nem tudo que desejamos, que efetivamente queremos, iremos, de fato, conseguir. Lutamos por aquilo que queremos atingir e podemos conseguir pequenas, médias e grandes vitórias. Lidar com o desejo possível, portanto, torna o professor capaz de reestruturar toda sua prática e sua posição social de trabalho. Finalmente, a questão política, que o professor eficiente no seu ambiente escolar e na sua própria prática, tem de incorporar no cotidiano de seu saberfazer, tem que se mostrar contínua: participar das lutas cotidianas da comunidade escolar, representar a coordenação, estimular a participação de seus alunos no grêmio estudantil, participar do colegiado. Tudo isso significa, igualmente, estar constantemente presente na máquina de organização da prática pedagógica. Porque é muito comum existir processos nos quais nós não nos envolvemos na vida escolar e de repente não vemos as possibilidades de movimento. Por isso a participação no 
ambiente escolar deve estar pressuposta na prática docente. Não existe a possibilidade de tornarmo-nos professores que busca o envolvimento com os alunos sem uma participação política na escola na qual se trabalha.

Para concluir (ou provocar novos desdobramentos) apresento um rol de discussões conceituais e práticas que tenta contemplar a formação do professor. Em primeiro lugar, deve ser considerada a luta pela busca de sua autonomia, conseguida no âmbito das demais lutas presentes no cotidiano escolar. Em segundo lugar, a reflexão sobre questões conceituais devem estar ligadas às operacionais na atuação do professor de ensino básico em geral. Isso deve ser estendido sobre a didática, os conceitos e temas das ciências específicas, o funcionamento da instituição-escola, o Estado e sua legislação em vigor, o papel dos códigos pedagógicos, pois muitos de nós quando chegamos ao ambiente escolar, após nos formarmos, não sabemos o papel da supervisora pedagógica, qual o papel de um serviço educacional, o que cabe a esses profissionais que estão no ambiente escolar.

Nós profissionais, ao iniciarmos nossa carreira docente, não temos esse domínio. É necessário ao profissional de educação que ele saiba como funciona a máquina escolar. Somente assim ele pode participar intensamente do fato político, como eu falei anteriormente, levantar questões filosóficas sobre a complexidade do mundo vivido, sobre as metodologias de ensino e do aprendizado, e finalmente, isso é uma demanda para que possamos ter o domínio dos recursos técnicos e da metodologia em sala de aula.

Em terceiro lugar, temos de ficar atentos às inovações tecnológicas. É comum ouvirmos que o professor não domina o uso da internet, que não sabe lidar com e-mails, negando essas tecnologias. Contudo, lembremos para que não se faça equívocos, pois não estou fazendo aqui uma defesa da técnica em si mesma, mas ao mesmo tempo eu não posso acreditar que um professor se negue a usar essas novas tecnologias e que tenha medo daquelas inovações, no momento em que ele tem como objeto, além da relação ensino-aprendizagem, a mediação do conhecimento. O docente que desejar conhecer e aprimorar o seu saber-fazer diante dessas velozes transformações, envolvido na busca de sua autonomia precisa aprender com seu aluno, deve aprender a usar a internet e a acessar o "facebook", "msn", entre outras redes sociais, muito utilizadas por seus alunos. Precisa entender que essas são linguagens eficientes e que fazem parte da realidade do grupo social. 